\title{
Hemp-derived activated carbons for supercapacitors
}

\author{
Wei Sun ${ }^{a}$, Stephen M. Lipka ${ }^{b}$, Christopher Swartz ${ }^{b}$, David Williams ${ }^{c}$, and Fuqian Yang ${ }^{a}$ * \\ ${ }^{a}$ Materials Program, Department of Chemical and Materials Engineering \\ University of Kentucky, Lexington, KY 40506, United States \\ ${ }^{\mathrm{b}}$ Center for Applied Energy Research, \\ University of Kentucky, Lexington, KY 40511, United States \\ ${ }^{\mathrm{c}}$ Department of Plant and Soil Sciences \\ University of Kentucky, Lexington, KY 40546, United States
}

* Corresponding authors: Stephen M. Lipka, steve.lipka@uky.edu

Fuqian Yang, fyang2@uky.edu 


\begin{abstract}
Activated carbons are prepared from raw hemp stem (hurd and bast) via hydrothermal processing and chemical activation. Both hemp bast and hemp hurd are converted into activated carbons of low-dimensional structures under certain experimental conditions. The experimental results show that hemp hurd is a better precursor than hemp bast for the preparation of activated carbons. The activated carbons are used to construct the electrodes of supercapacitor cells. The electrochemical performance of the activated carbons used in the supercapacitor cells is dependent on hydrothermal processing conditions and the mass ratio of $\mathrm{KOH} /$ biochar in the chemical activation. Excellent electrochemical performance metrics are achieved, including a specific capacitance of $160 \mathrm{~F} / \mathrm{g}$, and a high energy density of $19.8 \mathrm{Wh} / \mathrm{kg}$ at a power density of $21 \mathrm{~kW} / \mathrm{kg}$. Both the specific capacitance and capacitance retention increase with the increase of surface area and mesopore fraction. A simple relationship between the specific area capacitance and the fraction of micropores is proposed, via the rule of mixtures, and is supported by the experimental results. This relationship reveals the effect of the distribution of pore sizes on the specific area capacitance of electrochemical double layer capacitors.
\end{abstract}




\section{Introduction}

Electrochemical double layer capacitors (EDLCs) are an attractive energy storage device, which store energy in an electrical double layer (EDL) of electrolyte ions at the electrode/electrolyte interface ${ }^{1,2}$. In comparison with lithium-ion batteries, EDLCs have much higher charge and discharge rates, and better cycle life ${ }^{3}$ and possess higher energy densities than traditional capacitors. Various materials have been used in the electrodes of electrochemical double layer capacitors, including carbon-based materials ${ }^{4}$, metal oxides ${ }^{5,6}$ and conductive polymeric materials ${ }^{7}$, among which activated carbonaceous materials have attracted great interest due to large surface area ${ }^{8}$, porous structures, good conductivity and good physical and chemical stability ${ }^{9,10}$.

Graphene is an attractive carbonaceous material with high surface area, intrinsic conductivity, mechanical strength and electrochemical stability. The two-dimensional sheet structure of graphene allows fast transportation of electrolyte ions during charging and discharging. In addition, chemical activation can significantly increase the porosity of graphene, which can improve the electrochemical performance ${ }^{8}$. However, it is very difficult to produce large quantities of graphene by chemical vapor deposition via thermal catalytic decomposition of gaseous hydrocarbons on the surface of some metals. Hydrothermal synthesis is a simple and economical method to produce micro/nano-scale carbon spheres with controllable sizes, using small molecules (i.e. xylose, glucose) ${ }^{11-13}$ or macromolecules (i.e. starch, cellulose) ${ }^{14,15}$ as precursors. Various carbonaceous materials, i.e. carbon spheres ${ }^{16}$, carbon nanotubes ${ }^{17}$, carbon fibers ${ }^{18}$, etc. also have been prepared from biomass via hydrothermal synthesis. These carbonaceous materials have been utilized as active materials in electrochemical energy storage after thermal processing, and exhibit good electrochemical performance. 
Hemp, which can grow quickly in various climates, has various applications, including building, food, medicine, cloth, oil, etc. ${ }^{19}$ Recently, Wang et al. ${ }^{20}$ prepared activated graphene from the hemp-bast fiber via hydrothermal processing and chemical activation. They demonstrated that hemp-derived graphene has high surface area and large amount of mesopores, and the supercapacitor electrode made from the hemp-derived graphene exhibits good electrochemical performance. Both high capacitance and energy density were achieved in an organic electrolyte at different temperatures. However, they only used the hemp-bast fiber in the study, which is $20-25 \%$ biomass of hemp ${ }^{21}$. There is still $75-80 \%$ biomass of hemp, the hemp stem, which likely can be carbonized and activated for the applications of energy storage. Hydrothermal synthesis is an effective approach for the conversion of bio-wastes and biomass. Given the potential applications of hemp-derived carbonaceous materials in energy storage, both hemp bast and hurd are utilized as precursors in this work to prepare activated carbons for EDLCs via hydrothermal synthesis. The activated carbons are used to prepare the electrodes of EDLCs, and the electrochemical characteristics of the EDLCs with an organic electrolyte are investigated. The rule of mixtures is used to develop a simple relationship for qualitative explanation of experimental observation.

\section{Experimental detail}

\section{Material preparation}

The activated carbons of low-dimensional structures were prepared by hydrothermal synthesis, which was followed by chemical activation. Raw hemp bast and hurd were used as the precursors for hydrothermal synthesis. Hemp bast or hurd $(9.0 \mathrm{~g})$ was added to $300 \mathrm{~mL}$ of deionized (DI) water or 1 wt.\% sulfuric acid in a Teflon liner, which was then put into a steel autoclave and was sealed before the start of the hydrothermal synthesis. The temperature of the 
solution in the Teflon liner was gradually increased to $200{ }^{\circ} \mathrm{C}$ in $1 \mathrm{hr}$, in which the hemp bast or hurd was hydrothermally treated for $24 \mathrm{hr}$ at $200{ }^{\circ} \mathrm{C}$. The hydrothermal product (named as biochar) was collected by filtration, washed in DI water several times and dried overnight at 60 ${ }^{\circ} \mathrm{C}$ in vacuum. The biochar was mixed with potassium hydroxide in different mass ratios (biochar/KOH) of 1:1, 1:3 and 1:5. The mixture was thoroughly ground in a mortar and then heated to $800{ }^{\circ} \mathrm{C}$ in a nitrogen atmosphere with a heating rate of $20^{\circ} \mathrm{C} / \mathrm{min}$, and the biochar was chemically activated at $800{ }^{\circ} \mathrm{C}$ for $1 \mathrm{hr}$. The activated carbon was washed with DI water until the $\mathrm{pH}$ value became 7. The activated carbon was then dried at $90{ }^{\circ} \mathrm{C}$ for $12 \mathrm{hr}$.

\section{Materials characterization}

The activated carbons were characterized by a scanning electron microscope (Hitachi S4800). To determine the surface area and pore of the activated carbons, the nitrogen adsorptiondesorption isotherms were measured by an automated gas adsorption analyzer (Micromeritics surface characterization, Norcross, GA).

\section{Preparation of supercapacitor cells}

A dry-mixture method was used to prepare electrodes from the activated carbon. The activated carbon was mixed with graphite as conductive agent and PTFE (polytetrafluoroethylene) as binder in a mass ratio of 92:5:3. The mixture was heat-treated at 110 ${ }^{\circ} \mathrm{C}$ for 30 min, which was then milled in a mortar until a sheet was produced. The sheet was then rolled to a sheet with a thickness of $65-80 \mu \mathrm{m}$. Circular discs with a $12 \mathrm{~mm}$ diameter were punched out from the sheet and used as the electrodes of electrochemical double layer capacitors. The prepared electrodes were placed on two carbon current collectors, separately, which were assembled together with a polymeric separator (CELGARD 3581) between them. The organic electrolyte 1.8M TEMABF4/PC. 


\section{Electrochemical measurement}

Cyclic voltammetry (CV) and constant current charge/discharge experiments were performed at room temperature with a Gamry G750 Potentiostat. Electrochemical impedance spectroscopy was carried out with a Schlumberger SI 1260 impedance/gain-phase analyzer. ECC-STD test cell (EL-CELL, Germany) was used for electrochemical characterization.

\section{Results and discussion}

Materials characterization

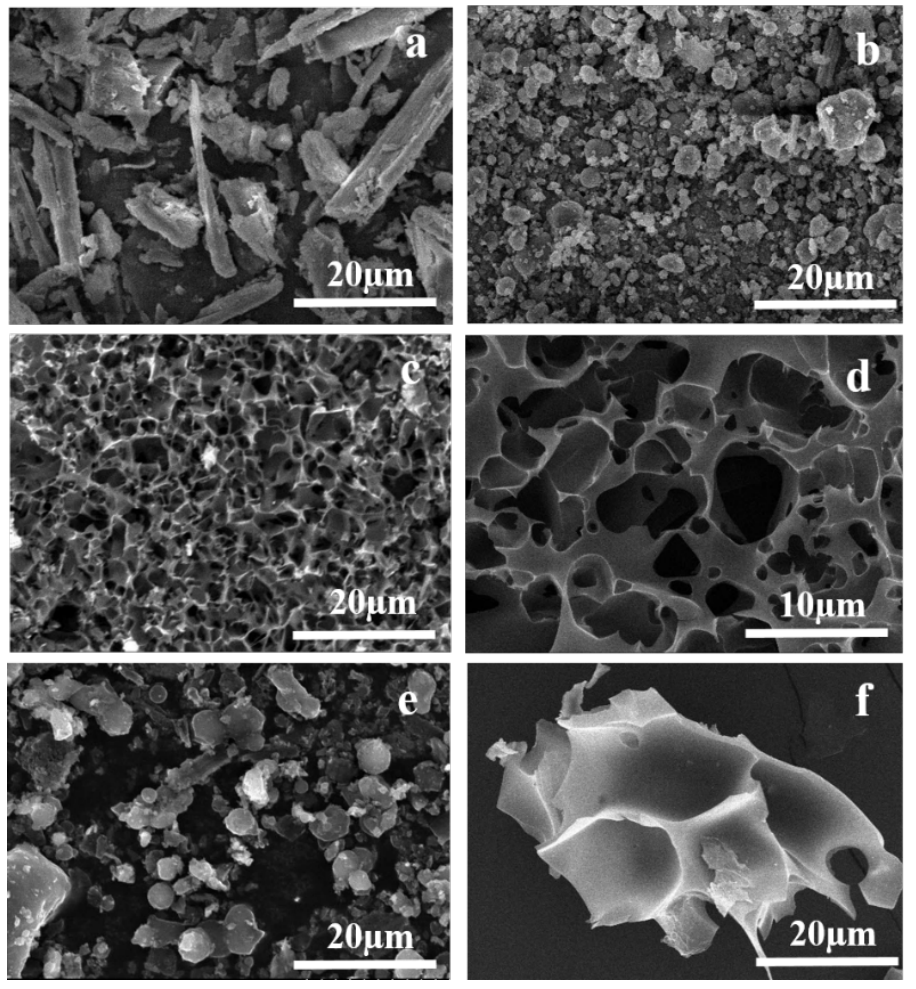

Figure 1. SEM images of the biochar derived from the hemp bast in different liquid solutions: (a) DI water, (b) 1 wt.\% $\mathrm{H}_{2} \mathrm{SO}_{4}$; SEM images of the chemically activated carbons with different mass ratios of $\mathrm{KOH}$ to biochar: (c-d) 3:1, (e) 1:1, and (f) 5:1 (activation temperature: $800{ }^{\circ} \mathrm{C}$ )

Figures 1a and 1b show the morphologies of the biochars derived from the hemp bast via the hydrothermal synthesis at $200{ }^{\circ} \mathrm{C}$ in two different solutions of DI water and 1 wt. $\% \mathrm{H}_{2} \mathrm{SO}_{4}$, respectively. The hydrothermal reaction significantly broke up the long fiber structures of the 
raw hemp bast into microscale structures. The morphologies of the biochar are dependent on the liquid solution used. The biochar produced in DI water maintained the fiber-like structures, while the biochar produced in sulfuric acid was broken up into irregular chips of smaller sizes.

Based on the precursor, hydrothermal medium and the mass ratio of $\mathrm{KOH} / \mathrm{biochar}$ in the chemical activation, the activated carbons are denoted as Bast-a/b-x or Hurd-a/b-x with $a / b$ representing the liquid solution: a for $\mathrm{H}_{2} \mathrm{SO}_{4}$, b for DI water, and $\mathrm{x}$ of 1,3 or 5 representing 1:1, 3:1 or 5:1, respectively. The morphological difference between the biochars produced in different liquid solutions suggests that the liquid solution plays an important role in the hydrothermal reaction. The sulfuric acid enhances the decomposition of hemp fibers during the hydrothermal reaction. Note that the hydrothermal processing of the hemp bast and hurd in an alkaline environment was also performed, and no small pieces of the hemp bast and hurd were produced. The materials treated by the hydrothermal process were presented in the form of bulk materials similar to those before the hydrothermal processing.

The morphologies of the activated carbons change with the mass ratio of $\mathrm{KOH} / \mathrm{biochar}$. Figures 1c and 1d show the morphologies of the activated carbon of Bast-a-3. The activated carbon of Bast-a-3 displays a porous thin sheet of 3D structure, which can cover a relatively large area. The thin sheet is very brittle and can be broken easily up into smaller chips. Bast-a-1 consists of irregular micro-particles (Fig. 1e), and Bast-a-5 consists of fragments of porous structures with large hole sizes.

The difference between the morphologies of the biochars (Fig. 1b) and the activated carbons (Figs. 1c-1f) indicates that the chemical activation is a complicated process, rather than a simple decomposition or separation. The melting point of $\mathrm{KOH}$ is $406{ }^{\circ} \mathrm{C}$. At $800{ }^{\circ} \mathrm{C}$ under a high pressure, there exists a liquid phase of $\mathrm{KOH}$, and the biochar reacts with $\mathrm{KOH}$ and forms a 
structure with completely different morphologies from the biochar. The activated carbons from the hurd-biochars, which were derived from different solutions, exhibit similar morphologies for the same activation conditions.
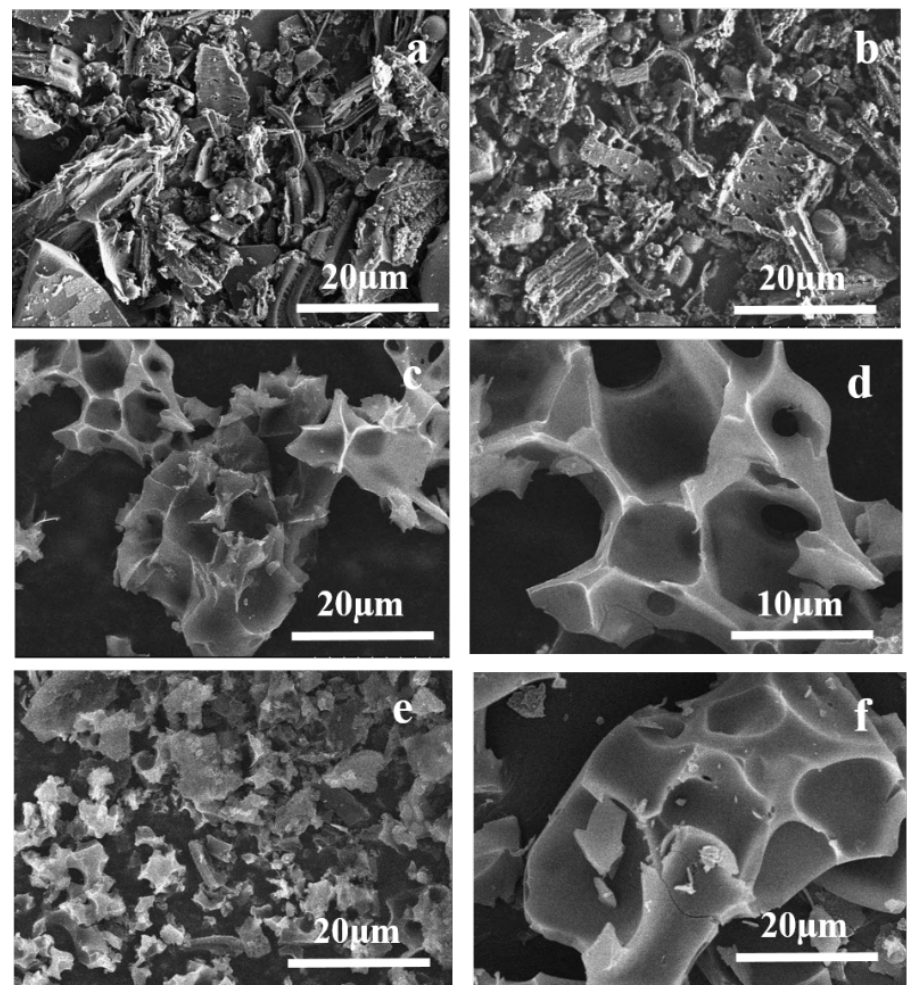

Figure 2. SEM images of the biochars derived from the hemp hurd in different liquid solutions: (a) DI water, (b) 1 wt.\% $\mathrm{H}_{2} \mathrm{SO}_{4}$; SEM images of the chemically activated carbons with different mass ratios of $\mathrm{KOH}$ to biochar: (c-d) 3:1, (e) 1:1, and (f) 5:1 (activation temperature: $800{ }^{\circ} \mathrm{C}$ )

Figures 2a-2b show the morphologies of the biochars derived from hemp hurd via the hydrothermal synthesis at $200{ }^{\circ} \mathrm{C}$ in two different solutions of DI water and $1 \mathrm{wt} . \% \mathrm{H}_{2} \mathrm{SO}_{4}$. The morphologies of the bast-biochars formed are dependent on the liquid solutions used, while the morphologies of the hurd-biochars are relatively the same, independent of the liquid solutions. However, the activated carbons derived from the bast-biochars have similar structure to those derived from the hurd-biochars for the same activation conditions. The similar structure of the 
activated carbons indicates the same role of the reaction between $\mathrm{KOH}$ and biochar in the formation of different morphologies.

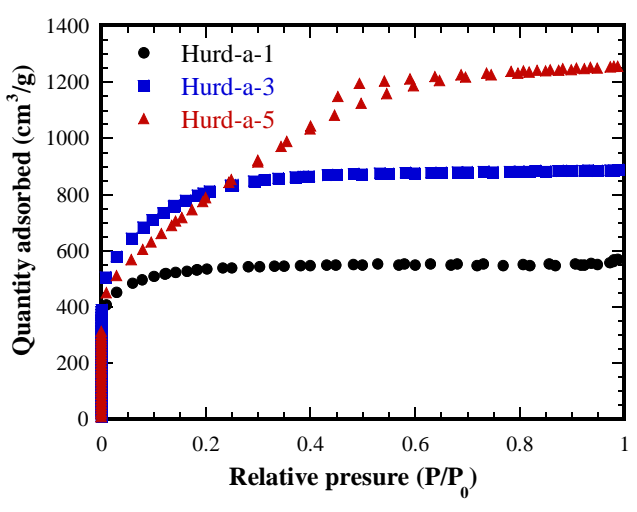

(a)

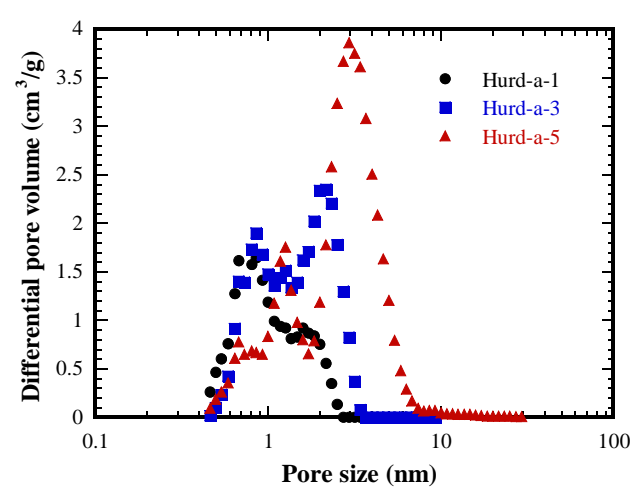

(b)

Figure 3. Surface properties of the activated carbons of Hurd-a-x: (a) nitrogen adsorptiondesorption isotherms, and (b) distribution of pore sizes calculated from the adsorption isotherms via the DFT (density functional theory) method

It is known that chemical activation of carbon materials can lead to the formation of porous structures and an increase in surface area. Figure 3a shows the nitrogen adsorption-desorption isotherms for the activated carbons of Hurd-a-x. The isotherms for the activated carbons of Hurd-a-1 and Hurd-a-3 show a Type I profile, which is a typical microporous profile, while the isotherm of Hurd-a-3 shows a broad knee indicating a wide distribution of pore sizes. The isotherm of Hurd-a-5 is similar to a Type IV profile, suggesting the presence of a mesoporous structure. From the distribution of the pore sizes of the activated carbons (Fig. 3b), one can note that the average size of pores and fraction of mesopores increase with the increase of the mass ratio of $\mathrm{KOH}$ to biochar, in accord with the results shown in the isotherms (Fig. 3a). 
Table 1. Surface area parameters of the hemp-derived activated carbons

\begin{tabular}{|c|c|c|c|c|c|c|c|}
\hline Materials & $\begin{array}{c}\mathrm{S}_{\text {BET }} \\
\left(\mathrm{m}^{2} / \mathrm{g}\right)\end{array}$ & $\begin{array}{c}\mathrm{S}_{\mathrm{DFT}} \\
\left(\mathrm{m}^{2} / \mathrm{g}\right)\end{array}$ & $\begin{array}{c}\mathrm{V}_{\text {total }} \\
\left(\mathrm{cm}^{3} / \mathrm{g}\right)\end{array}$ & $\begin{array}{c}\mathrm{S}_{\text {micro }}\left(\mathrm{m}^{2} / \mathrm{g}\right) \\
(\operatorname{area} \%)\end{array}$ & $\begin{array}{c}\mathrm{S}_{\text {meso }}\left(\mathrm{m}^{2} / \mathrm{g}\right) \\
(\mathrm{area} \%)\end{array}$ & $\begin{array}{c}\mathrm{V}_{\text {micro }}\left(\mathrm{cm}^{3} / \mathrm{g}\right) \\
(\mathrm{vol} \%)\end{array}$ & $\begin{array}{c}\mathrm{V}_{\text {meso }}\left(\mathrm{cm}^{3} / \mathrm{g}\right) \\
(\mathrm{vol} \%)\end{array}$ \\
\hline Hurd-a-1 & 1910 & 1504 & 0.7249 & $1472(97.9)$ & $32(2.9)$ & $0.67(92)$ & $0.06(8)$ \\
\hline Hurd-a-3 & 2879 & 1853 & 1.1605 & $1609(86.9)$ & $244(13.1)$ & $0.86(74)$ & $0.30(26)$ \\
\hline Hurd-a-5 & 2801 & 1736 & 1.7096 & $1003(57.8)$ & $733(42.2)$ & $0.53(31)$ & $1.18(69)$ \\
\hline Hurd-b-5 & 2446 & 1476 & 1.05922 & $1127(76.3)$ & $349(23.6)$ & $0.60(57)$ & $0.45(43)$ \\
\hline Bast-a-5 & 2671 & 1663 & 1.76229 & $916(55.1)$ & $747(44.9)$ & $0.48(27)$ & $1.28(73)$ \\
\hline Bast-b-5 & 1909 & 1078 & 0.86267 & $916(85.1)$ & $162(14.9)$ & $0.54(63)$ & $0.32(37)$ \\
\hline $\begin{array}{c}\text { Bast-biochar } \\
(\text { DI water })\end{array}$ & 0.59 & 0.65 & 0.0133 & $0(0)$ & $0.5(89.3)$ & $0(0)$ & $0.008(60.1)$ \\
\hline $\begin{array}{c}\text { Bast-biochar } \\
\left.\left(\mathrm{H}_{2} \mathrm{SO}\right)_{4}\right)\end{array}$ & 1.85 & 0.71 & 0.0258 & $0(0)$ & $0.22(31.0)$ & $0(0)$ & $0.002(77.5)$ \\
\hline $\begin{array}{c}\text { Hurd-biochar } \\
(\text { DI water })\end{array}$ & 6.9 & 3.05 & 0.0523 & $0(0)$ & $2.59(84.9)$ & $0(0)$ & $0.036(68.8)$ \\
\hline $\begin{array}{c}\text { Hurd-biochar } \\
\left(\mathrm{H}_{2} \mathrm{SO}_{4}\right)\end{array}$ & 0.97 & 0.29 & 0.0136 & $0(0)$ & $0.059(20.3)$ & $0(0)$ & $0.001(7.4)$ \\
\hline
\end{tabular}

Table 1 lists the surface properties of the activated carbons derived from hemp under different conditions. Here, $S_{\mathrm{BET}}$ was calculated by the BET (Brunauer-Emmett-Teller) method; $\mathrm{S}_{\mathrm{DFT}}$ was calculated by the DFT (density functional theory) method. The total pore volume was determined at a relative pressure of 0.98 . The surface areas $\left(S_{\text {micro }}\right.$ and $\left.S_{\text {meso }}\right)$ and pore volumes ( $\mathrm{V}_{\text {micro }}$ and $\mathrm{V}_{\text {meso }}$ ) of the micropores and mesopores were calculated by the DFT method.

Generally, the surface area and percentage of mesopores increase with the increase of the mass ratio of $\mathrm{KOH}$ to biochar. However, the activated carbon of Hurd-a-3 has larger surface area and fraction of mesopores than Hurd-a-5. The reason for such behavior is unclear. It is likely associated with the chemical reaction between $\mathrm{KOH}$ and the hurd-biochar. There might exist an excess amount of $\mathrm{KOH}$ for the chemical activation with the mass ratio of $\mathrm{KOH}$ to biochar being $5: 1$, which limits the formation of more mesopores. For the same activation conditions, the 
activated carbons derived from the hurd have larger surface area and fraction of mesopores in comparison with those derived from the bast. High surface areas up to $2800 \mathrm{~m}^{3} / \mathrm{g}$ and up to 70 vol.\% of mesopores can be achieved under certain conditions. The surface properties of the biochars prepared by different experimental conditions are also listed in Table 1. The biochars have much lower surface areas and pore volumes than the corresponding activated carbons. Also, the biochars do not possess micropores. The surface area and pore volume of the mesopores and macropores in the biochars are much less than the corresponding activated carbons, although there are large fractions of mesopores and macropores (pores with a diameter larger than $50 \mathrm{~nm}$ ). It needs to point out that the large fractions of mesopores and macropores might be attributed to the separation between biochar particles and surface textures, which cannot represent the intrinsic fraction of the pores in each individual biochar particles. The activation is a key process to form porous structures in activated carbons with a high surface area.

In general, the surface properties of the biochars vary significantly with the hydrothermal conditions, and it is not necessary for a biochar with a larger surface area to produce activated carbon with a larger surface area after chemical activation than the activated carbon produced from a biochar with a smaller surface area under the same activation conditions. There are various factors, such as the surface and chemical properties of biochars, which determine the surface properties of the corresponding activated carbons.

\section{Electrochemical performance of activated carbons}

Figure 4a depicts the Nyquist plot of the activated carbons of Hurd-a-x. The activated carbons possess a resistive nature in the high frequency range. The imaginary part of the resistance increases sharply in the region of low frequency, representing capacitive behavior from the formation of ionic and electronic charges of the electric double layer on the surface of 
micropores. In the middle frequency range, there is a shift from the capacitive behavior in the low frequency range to the resistive behavior in the high frequency range due to the dependence of the migration rate of ions into pores on the thicknesses of electrodes, porosity and other structural characteristics.

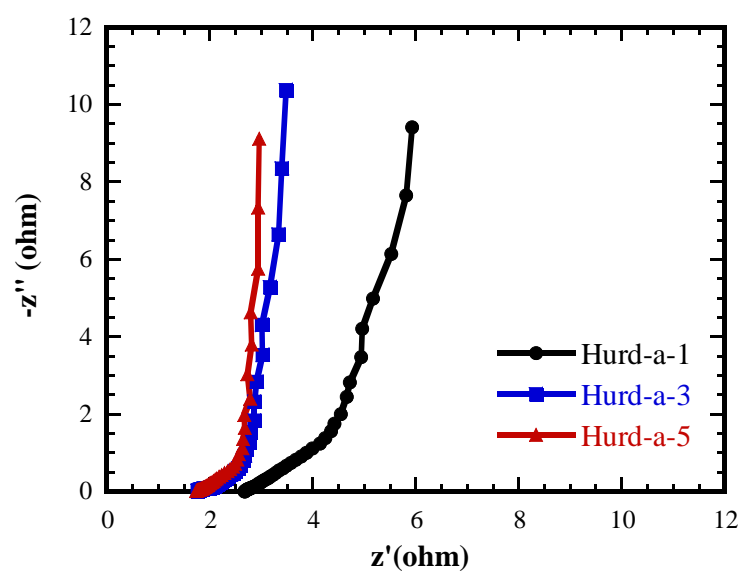

(a)

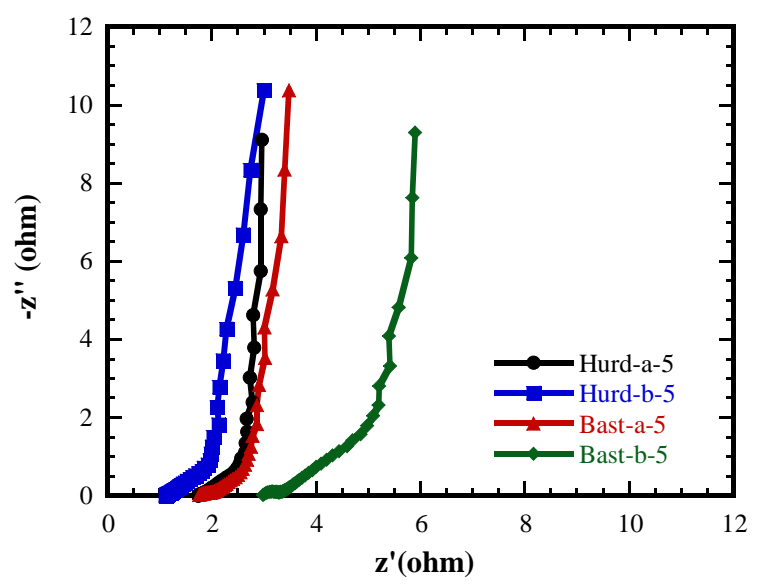

(c)

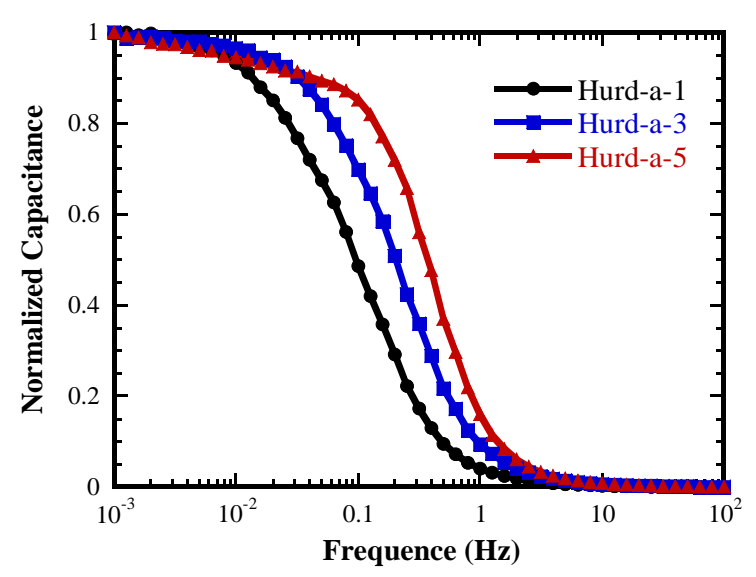

(b)

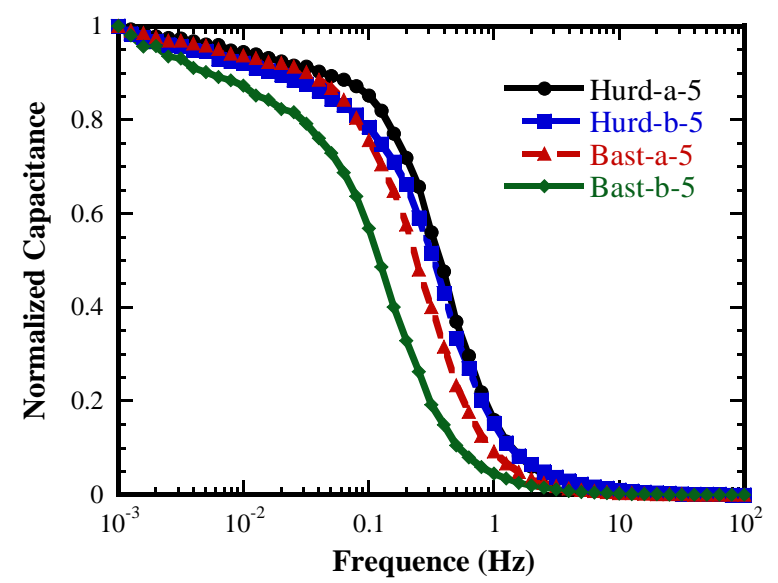

(d)

Figure 4. Nyquist plots of: (a) Hurd-a-x, and (c) activated carbons derived from various biochars (mass ratio of $\mathrm{KOH} / \mathrm{biochar}$ 5:1); variation of normalized capacitance with frequency: (b) Hurda-X, and (d) activated carbons derived from various biochars (mass ratio of $\mathrm{KOH} /$ biochar: 5:1); (operating voltage: $2 \mathrm{~V}$ ) 
The initiation point of the capacitive behavior corresponds to the "knee frequency" ${ }^{22,23}$, and the intercept with the horizontal axis corresponds to the equivalent series resistance (ESR) consisting of the contributions from the intrinsic resistances of electrodes, ions and the contact resistance between electrode and current collector. The EIS (Electrochemical Impedance Spectroscopy) results of different hemp-derived activated carbons are summarized in Table. 2. The ESR is 2.66 ohm for Hurd-a-1, 1.85 ohm for Hurd-a-3, and 1.77 ohm for Hurd-a-5. For the same electrolyte, the decrease of the ESR with the increase of the mass ratio of $\mathrm{KOH}$ to biochar indicates the decrease of the intrinsic resistance of the activated carbons likely due to the difference in structures. The resistance at the "knee frequency" is 4.92 ohm for Hurd-a-1, 2.86 ohm for Hurd-a-3, and 2.66 ohm for Hurd-a-5 in accord with the decreasing trend of the ESR with the increase of the mass ratio of $\mathrm{KOH}$ to biochar. From the Nyquist plots of the activated carbons derived from different biochars in Fig. 4c, the ESRs for Hurd-a-5, Hurd-b-5 and Bast-a5 are around 1.1-1.8 ohm, and the ESR for Bast-b-5 is $2.97 \mathrm{ohm}$.

Table 2. EIS results of the hemp-derived activated carbons

\begin{tabular}{|c|c|c|c|}
\hline Materials & ESR (ohm) & $\begin{array}{c}\text { Resistance at “knee } \\
\text { frequency” (ohm) }\end{array}$ & $\begin{array}{c}\text { Frequency at 50\% of the } \\
\text { largest capacitance (Hz) }\end{array}$ \\
\hline Hurd-a-1 & 2.66 & 4.92 & 0.082 \\
\hline Hurd-a-3 & 1.85 & 2.86 & 0.20 \\
\hline Hurd-a-5 & 1.77 & 2.66 & 0.38 \\
\hline Hurd-b-5 & 1.11 & 1.34 & 0.31 \\
\hline Bast-a-5 & 1.73 & 2.17 & 0.26 \\
\hline Bast-b-5 & 2.97 & 4.97 & 0.13 \\
\hline
\end{tabular}

It is known the change of the "knee frequency" is associated with the porous structures of the materials used in electrodes. Mesopores have a better accessibility than micropores for large organic ions ( $\left.\mathrm{TEMA}^{+} / \mathrm{BF}^{-}\right)$, leading to less dependence of the real part of the impedance on 
frequency for materials with more mesopores. From the Nyquist plots of the activated carbons derived from different biochars in Fig. 4c, one can conclude that the Hurd-a-5 has similar porous structures to the Bast-a-5. This trend is consistent with the results listed in Table 1.

Figures $4 \mathrm{~b}$ and $4 \mathrm{~d}$ show the variation of the normalized capacitance with frequency for the biochars of Hurd-a-x and activated carbons derived from various biochars, representing the frequency response of the capacitance of the systems. The capacitance decreases with increasing frequency, and there is a sharp decrease of the capacitance in the frequency range of 0.07-1 Hz. For the cells made from the activated carbons of Hurd-a-x, the frequency at $50 \%$ of the maximum capacitance is $0.082 \mathrm{~Hz}$ for Hurd-a- $1,0.20 \mathrm{~Hz}$ for Hurd-a-3, to $0.38 \mathrm{~Hz}$ for Hurd-a-5 (Fig. 4b). From Fig. 4d, one can note that the bast-derived activated carbons have lower frequencies at $50 \%$ of the maximum capacitance than the hurd-derived activated carbons, suggesting that the resistive behavior of the Hurd-derived activated carbons is more frequencydelayed than the bast-derived activated carbons.

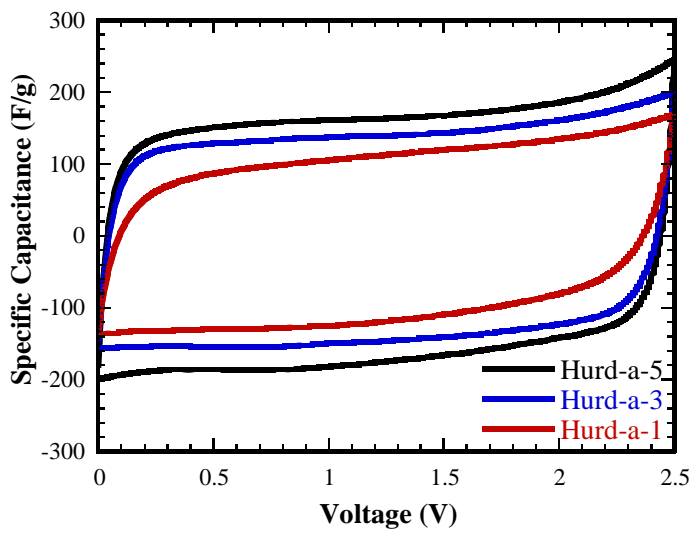

(a)

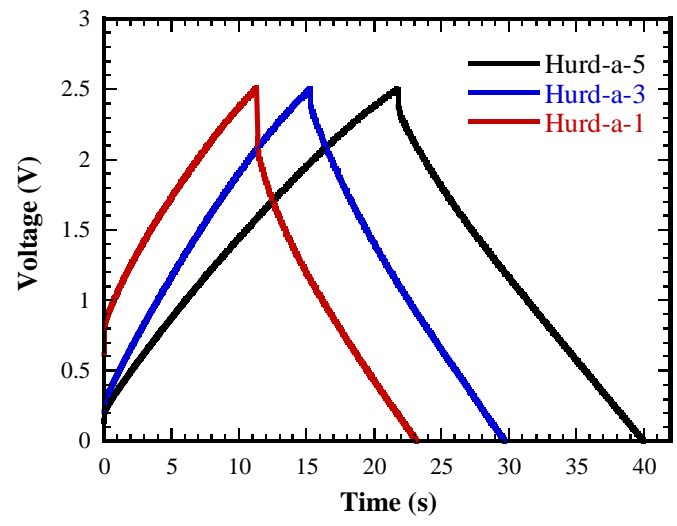

(b) 


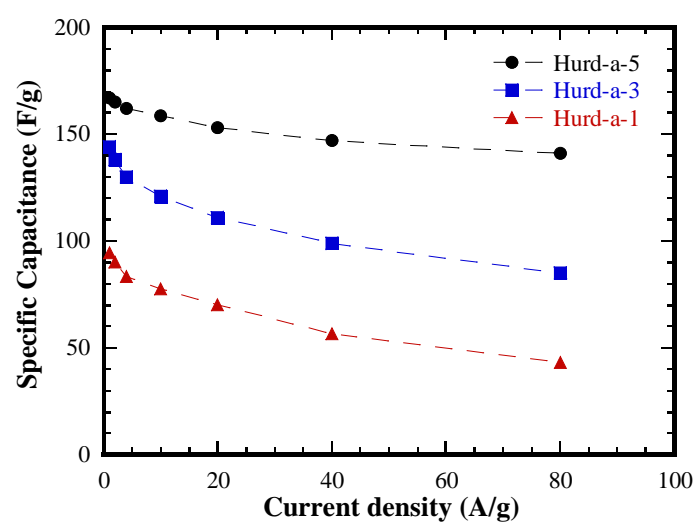

(c)

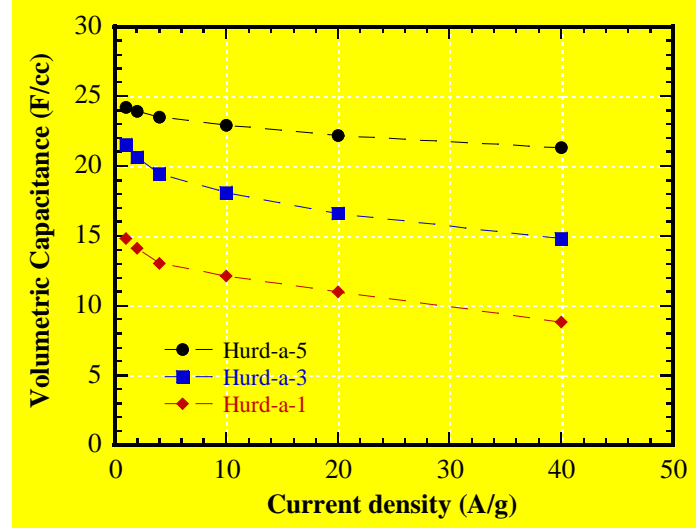

(d)

Figure 5. Electrochemical properties of the supercapacitor cells made from the activated carbons of Hurd-a-x: (a) CV curves (scan rate: $100 \mathrm{mV} / \mathrm{s}$ ), (b) galvanostatic charge/discharge curves (current density: $10 \mathrm{~A} / \mathrm{g}$ ), (c) variation of specific capacitance with current density, and (d) variation of volumetric capacitance with current density.

Figure 5a shows the cyclic voltammogram (CV) for the supercapacitor cells made from the activated carbons of Hurd-a-x. The quasi-rectangular shape of the CV curves is observed for the supercapacitor cells made from Hurd-a-5 and Hurd-a-3, indicative of capacitive charge storage. This result implies rapid current response to the change of voltage from 0 to $2.5 \mathrm{~V}$ and fast ion transport during charging and discharging. The supercapacitor cell made from Hurd-a-1 exhibits less favorable electrochemical performance with relatively more distortion in the CV curve. The specific capacitance displays an increasing tendency from Hurd-a-1 to Hurd-a-5.

Figure $5 \mathrm{~b}$ shows the charge/discharge curves of the supercapacitor cells made from the activated carbons of Hurd-a-x. The current density was $10 \mathrm{~A} / \mathrm{g}$. The charge/discharge behavior is highly reversible, and the discharge curves display linear behavior, and are approximately symmetrical to the corresponding charge curves. The linear behavior of the charge/discharge curves demonstrates excellent capacitive characteristics of the supercapacitor cells. 
Table 3. Electrochemical performances of the supercapacitor cells made from the hemp-derived activated carbons

\begin{tabular}{|c|c|c|c|c|}
\hline Materials & IR drop (V) & $\begin{array}{c}\mathrm{C}_{1} \text { (specific capacitance } \\
\text { at } 1 \mathrm{~A} / \mathrm{g})(\mathrm{F} / \mathrm{g})\end{array}$ & $\begin{array}{c}\mathrm{C}_{80} \text { (specific capacitance } \\
\text { at 80A/g) }(\mathrm{F} / \mathrm{g})\end{array}$ & $\mathrm{C}_{80} / \mathrm{C}_{1}$ \\
\hline Hurd-a-1 & 0.35 & 94 & 43 & $50.8 \%$ \\
\hline Hurd-a-3 & 0.1 & 144 & 85 & $72.4 \%$ \\
\hline Hurd-a-5 & 0.12 & 167 & 141 & $83.9 \%$ \\
\hline Hurd-b-5 & 0.1 & 136 & 78 & $52.9 \%$ \\
\hline Bast-a-5 & 0.11 & 146 & 102 & $70.8 \%$ \\
\hline Bast-b-5 & 0.42 & 103 & 43 & $34.0 \%$ \\
\hline
\end{tabular}

Table 3 summarizes the electrochemical performance of the supercapacitor cells made from the hemp-derived activated carbons. It is known that the IR drop is dependent on the conductivity and porous structure of the materials used in the electrodes of a supercapacitor ${ }^{24}$. The IR drop is $0.12 \mathrm{~V}$ for the supercapacitor cells made from the activated carbon of Hurd-a-5, $0.1 \mathrm{~V}$ for the supercapacitor cells made from the activated carbon of Hurd-a-3, and $0.35 \mathrm{~V}$ for the supercapacitor cells made from the activated carbon of Hurd-a-1. The IR drop for the supercapacitor cells made from the activated carbon of Hurd-a-5 is larger than that for the supercapacitor cells made from the activated carbon of Hurd-a-3. The mechanism for this behavior is unclear. Generally, IR drop increases with the increase of the pore length for the same pore size. Such behavior suggests that there likely exist other parameters, such as the average length of pores and defects, determining the IR behavior of the activated carbons. Hurda-5 might have mesopores with an average pore length longer than Hurd-a-3.

Keh and Anderson ${ }^{25}$ analyzed the motion of a colloidal sphere of radius $a$ in a cylindrical pore of radius $b$ under an action of electric field, $E_{0}$, and obtained the electrophoretic velocity of the colloidal sphere, $U$, as 


$$
U=\frac{1}{4 \pi \eta} \varepsilon\left(\varsigma_{p}-\varsigma_{w}\right) E_{0}\left(1-1.29\left(\frac{a}{b}\right)^{3}+1.89\left(\frac{a}{b}\right)^{5}-1.03\left(\frac{a}{b}\right)^{6}+O\left(\frac{a}{b}\right)^{8}\right) \text { for } a / b<0.7 \text { (1) }
$$

where $\varsigma_{p}$ and $\varsigma_{w}$ are the zeta potentials of the sphere and of the pore wall, respectively, $\eta$ is the fluid viscosity, and $\varepsilon / 4 \pi$ is the fluid permittivity. According to Eq. (1), the electrophoretic velocity of the colloidal sphere decreases with the increase of the ratio of $a / b$. There is a larger resistance to the motion of the colloidal sphere in a smaller pore. For organic electrolyte ions of $\mathrm{TEMA}^{+} / \mathrm{BF}^{-}$with relatively large size, mesopores have a smaller ratio of the ionic radius to the pore radius than micropores, and mesopores have less resistance to the migration of ions than micropores. Mesopores are more favorable than micropores. The small fraction of mesopores (8 vol.\%) likely is one of the main reasons for the large IR drop in the supercapacitor cells made from the activated carbons of Hurd-a-1.

From the galvanostatic charge/discharge curves, the specific capacitance is calculated as

$$
C_{s p}=\frac{2 I}{m}\left(\frac{d V}{d t}\right)^{-1}
$$

where $I$ is the applied current intensity, $m$ is the mass of the activated carbon per electrode and $d V / d t$ is the slope of the discharge curve after the IR drop. Figure 5c shows the variation of specific capacitance with current density for the supercapacitor cells made from the activated carbons of Hurd-a-x. The specific capacitance increases with the increase of the mass ratio of $\mathrm{KOH} /$ biochar. The increase of the mass ratio of $\mathrm{KOH} /$ biochar improves the capacitance retention. At a current density of $80 \mathrm{~A} / \mathrm{g}$, the specific capacitance calculated from galvanostatic charge/discharge curves shown in Fig. S2a is $83.9 \%$ of that at $1 \mathrm{~A} / \mathrm{g}$ for the supercapacitor cells made from the activated carbon of Hurd-a-5, 72.4\% of that at $1 \mathrm{~A} / \mathrm{g}$ for the supercapacitor cells made from the activated carbon of Hurd-a-3, and 50.8\% of that at $1 \mathrm{~A} / \mathrm{g}$ for the supercapacitor cells made from the activated carbon of Hurd-a-1, as listed in Table 3. Both the specific 
capacitance and capacitance retention increase with the surface area and mesopore fraction. Such behavior is caused by the structure with a large fraction of mesopores that can provide a better pathway for rapid migration of ions, resulting in high capacitance retention in activated carbons with more mesopores.

Table 4. Parameters of each electrode and capacitances at $10 \mathrm{~A} / \mathrm{g}$ for different activated carbons

\begin{tabular}{|c|c|c|c|c|c|c|}
\hline Materials & $\begin{array}{c}\text { Electrode } \\
\text { diameter } \\
(\mathrm{mm})\end{array}$ & $\begin{array}{c}\text { Electrode } \\
\text { thickness } \\
(\mathrm{mm})\end{array}$ & $\begin{array}{c}\text { Electrode } \\
\text { Volume } \\
(\mathrm{cc})\end{array}$ & $\begin{array}{c}\text { Mass of activated } \\
\text { carbon in each } \\
\text { electrode }(\mathrm{g})\end{array}$ & $\begin{array}{c}\text { Specific } \\
\text { capacitance at } \\
10 \mathrm{~A} / \mathrm{g}(\mathrm{F} / \mathrm{g})\end{array}$ & $\begin{array}{c}\text { Volumetric } \\
\text { capacitance at 10A/g } \\
\text { (F/cc) }\end{array}$ \\
\hline Hurd-a-1 & 12 & 0.078 & 17.643 & 0.00276 & 77 & 12.045 \\
\hline Hurd-a-3 & 12 & 0.068 & 15.381 & 0.0023 & 121 & 18.093 \\
\hline Hurd-a-5 & 12 & 0.064 & 14.476 & 0.0021 & 158 & 22.920 \\
\hline Hurd-b-5 & 12 & 0.078 & 17.643 & 0.00304 & 117 & 20.133 \\
\hline Bast-a-5 & 12 & 0.066 & 14.929 & 0.0221 & 129 & 19.079 \\
\hline Bast-b-5 & 12 & 0.062 & 14.024 & 0.00217 & 82 & 12.688 \\
\hline
\end{tabular}

The volumetric capacitances of the supercapacitors were calculated from specific capacitance $\mathrm{C}_{s p}$ as

$$
C_{v o l}=\frac{C_{s p} \times m}{V o l}
$$

where $C_{s p}$ is specific capacitance $(\mathrm{F} / \mathrm{g}), m$ is the mass of the activated carbons in each electrode, and $\mathrm{Vol}$ is the volume of each electrode. Note that the volume of the binder and conductive additive were neglected in Eq. (3). Table 4 shows the geometrical parameters and the volumetric capacitance of the electrodes made from different activated carbons. At $10 \mathrm{~A} / \mathrm{g}$, the volumetric capacitances are 12.045 F/cc for Hurd-a-1, 18.093 F/cc for Hurd-a-3 and 22.920 F/cc for Hurd-a5, respectively. As shown in Fig. 5d, the volumetric capacitance also increases with the increase of the mass ratio of $\mathrm{KOH} / \mathrm{biochar}$ for other current densities, which is similar to the tendency of the specific capacitance, as shown in Fig. 5c. 


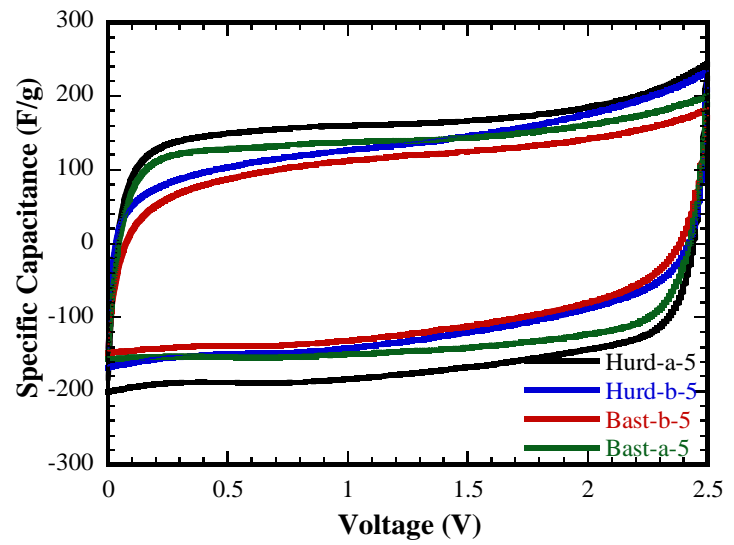

(a)

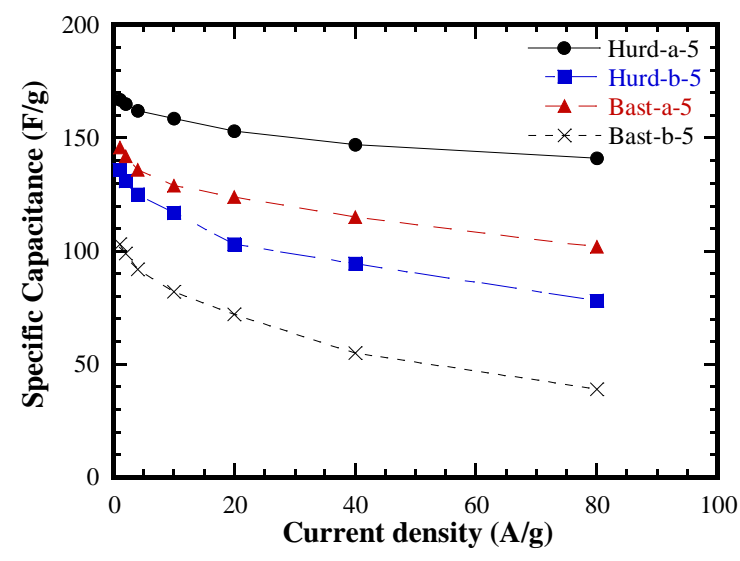

(c)

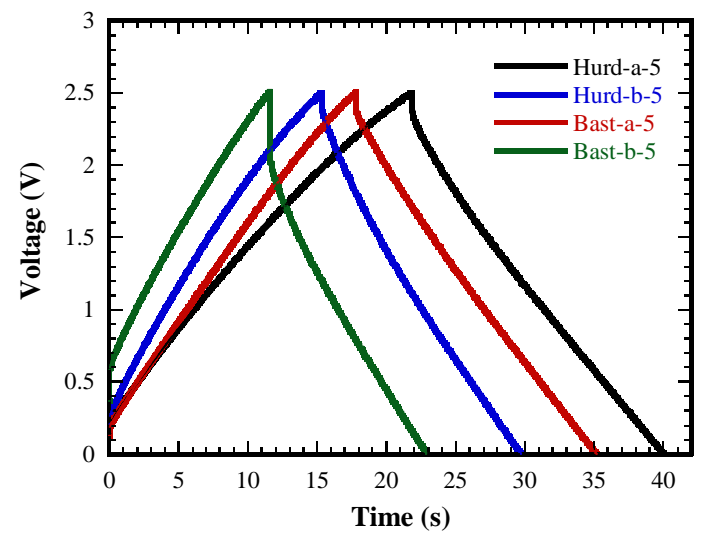

(b)

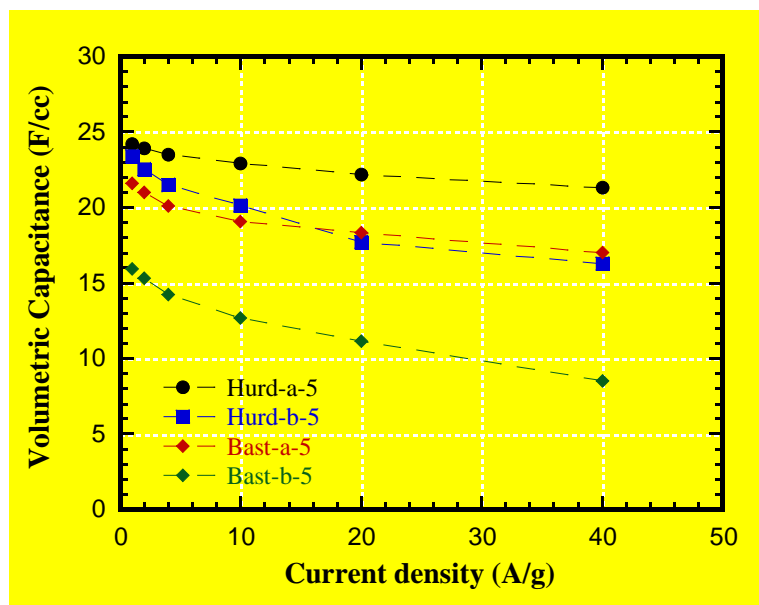

(d)

Figure 6. Electrochemical properties of the supercapacitor cells made from the activated carbons of different biochars: (a) CV curves (scan rate: $100 \mathrm{mV} / \mathrm{s}$ ), (b) galvanostatic charge/discharge curves (current density: $10 \mathrm{~A} / \mathrm{g}$ ), (c) variation of specific capacitance with current density, and (d) variation of volumetric capacitance with current density.

Figure 6a shows the cyclic voltammogram for the supercapacitor cells made from the activated carbons of different biochars with the same mass ratio of $\mathrm{KOH} /$ biochar (5:1). The scan rate was $100 \mathrm{mV} / \mathrm{s}$. The $\mathrm{CV}$ curves for the supercapacitor cells made from the activated carbons 
of Hurd-a-5 and Bast-a-5 are presented in a quasi-rectangular shape and enclose larger areas than those for the supercapacitor cells made from the activated carbons of Hurd-b-5 and Bast-b-5. The steeper charge and discharge segments and the larger enclosed area imply excellent electrochemical performance, which suggests that the hydrothermal processing with sulfuric acid can improve the electrochemical properties of the activated carbons derived from hemp-biochars.

The charge/discharge curves of the supercapacitor cells shown in Fig. 6b are highly linear and symmetric. As listed in Table 3, the IR drop is $0.12 \mathrm{~V}$ for the supercapacitor cells made from the activated carbon of Hurd-a-5, $0.1 \mathrm{~V}$ for the supercapacitor cells made from the activated carbon of Hurd-b-5, $0.11 \mathrm{~V}$ for the supercapacitor cells made from the activated carbon of Basta-5, and $0.42 \mathrm{~V}$ for the supercapacitor cells made from the activated carbon of Bast-b-5. The IR drops for the supercapacitor cells made from the activated carbons of Hurd-a-5, Hurd-b-5, and Bast-a-5 are approximately the same, even though the amount of mesopores for the activated carbons of Hurd-a-5 and Hurd-b-5 are much larger than that for the activated carbon of Bast-a-5. In contrast, there is little difference between the amounts of mesopores of the activated carbons of Bast-a-5 and Bast-b-5, while there is a large IR drop for the supercapacitor cells made from the activated carbon of Bast-b-5. In addition, the volume fraction of the mesopores for the activated carbon of Bast-b-5 (33 vol. \%) is larger than that for the activated carbon of Hurd-a-3 (26 vol.\%), while there is a much small IR drop $(0.1 \mathrm{~V})$ for the supercapacitor cells made from the activated carbon Hurd-a-3. Thus, the IR drop is also dependent on other factors, likely including conductivity, pore shape, pore length, connection of the pores, etc.

Figure 6c shows the variation of specific capacitance with current density for the supercapacitor cells made from the activated carbons of Hurd-x-5 and Bast-x-5. For the same mass ratio of 5:1 for $\mathrm{KOH} /$ biochar and liquid solution (DI water or sulfuric acid), the 
supercapacitor cells made from the activated carbons Hurd-x-5 possess higher capacitance than those made from the activated carbons of Bast-x-5. The specific capacitance gradually decreases with increasing current density, and the supercapacitor cells made from the activated carbons prepared by using sulfuric acid in the hydrothermal process feature high capacitance retention. At a current density of $80 \mathrm{~A} / \mathrm{g}$, the specific capacitance calculated from Fig. S2b is $83.9 \%$ of the capacitance measured at $1 \mathrm{~A} / \mathrm{g}$ for the supercapacitor cells made from the activated carbon of Hurd-a-5, which is much larger than 52.9\% for the cells made from the activated carbon of Hurdb-5. A similar trend is observed for the cells made from the activated carbon of Bast-a-5, with capacitance retentions of $70.8 \%$ and $34 \%$ for the activated carbon derived from Bast-a-5 and Bast-b-5, respectively. The specific capacitance of a supercapacitor can be likely increased via the use of sulfuric acid in the hydrothermal processing of biomass and biowastes.

Figure $6 \mathrm{~d}$ shows the variation of the volumetric capacitance with the current density for activated carbons made from various biochars. Similar to the specific capacitance, as shown in Fig. 6c, Hurd-a-5 always possesses the highest volumetric capacitance and Bast-b-5 has the lowest volumetric capacitance for the current densities used.

In general, sulfuric acid can assist the decomposition of biomass at a reasonable rate. The average size of the bast-derived biochar with the use of sulfuric acid in the hydrothermal processing is relatively smaller than that of the bast-derived biochar with the use of DI water. There is no detectable difference in the morphologies between the hurd-derived biochars with the use of sulfuric acid and DI water in the hydrothermal processing, while the hydrothermal yield with the use of DI water was $\sim 40 \%$ much higher than $\sim 15 \%$ with the use of sulfuric acid. These results suggest that sulfuric acid enhances the decomposition of hemp during hydrothermal processing, resulting in the formation of biochars with looser structures. In addition, the surface 
properties of the biochars treated with sulfuric acid are likely different from those treated with DI water, and the biochars treated with sulfuric acid likely are better precursors for the production of activated-porous carbons via the chemical activation.

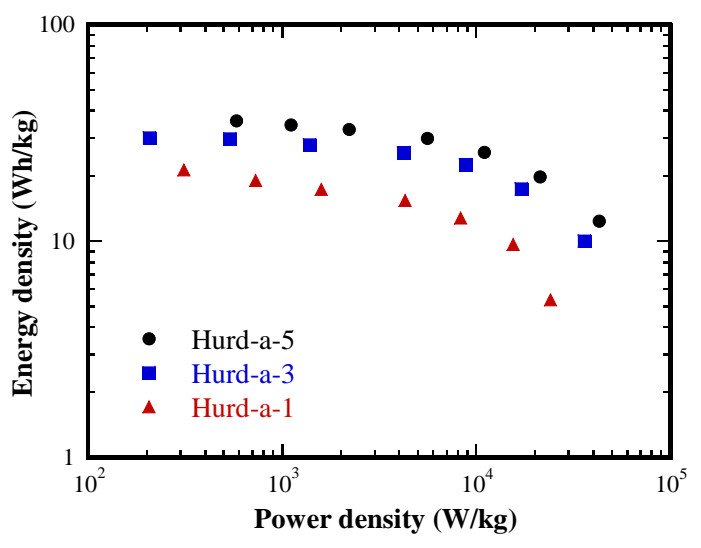

(a)

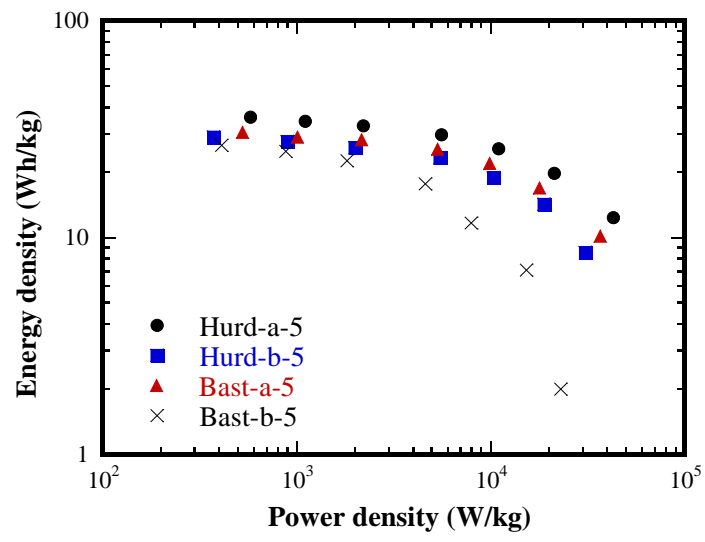

(b)

Figure 7. (a) Ragone plots for the supercapacitor cells made from the activated carbon of Hurda-x, and (b) Ragone plots for the supercapacitor cells made from the activated carbons derived from various precursors and liquid solutions (mass ratio of $\mathrm{KOH} / \mathrm{biochar:} \mathrm{5:1)}$

The specific energy and power density of a supercapacitor cell can be calculated from galvanostatic charge/discharge curves, using the following equations,

$$
E=\frac{C_{s p} V^{2}}{2} \text { and } P=\frac{E}{t}
$$

where $E$ is the specific energy density, $V$ is the voltage after the IR drop, and $t$ is the discharging time after the IR drop. Figure 7a shows the Ragone plots for the cells made from the activated carbon of Hurd-a-x, in which the calculation of the specific energy and power density was based on the mass of the activated carbon in the cell. The specific energy and power density increase with the increase of the mass ratio of $\mathrm{KOH} /$ biochar. For the supercapacitor made from the activated carbon of Hurd-a-5, a relatively high energy density of $19.8 \mathrm{Wh} / \mathrm{kg}$ was obtained at a 
power density of $\sim 21 \mathrm{~kW} / \mathrm{kg}$ for the operating voltage of $2.5 \mathrm{~V}$. A comparison of the Ragone plots for the supercapacitor cells made from the activated carbons derived from different precursors and liquid solutions is shown in Fig. 7b. The same activated condition was used for the activated carbons, and the mass ratio of $\mathrm{KOH} /$ biochar was 5:1. The symmetric carbon/carbon cells made from the activated carbons of Hurd-x-5 possess higher energy and power densities than the cells made from the activated carbons of Bast-x-5 prepared under the same chemical activation conditions. The decrease of the energy density with the power density is less pronounced for the cells made from the activated carbons of Hurd-x-5. Hydrothermal processing with the use of sulfuric acid can increase both energy and power densities. The energy density decreases faster with the increase of the power density for the activated carbons with larger resistance, i.e. Hurd-a-1 and Bast-b-5, since the dissipation of energy increases with increasing resistance of the activated carbons.

Asymmetric carbon/lithium hybrid supercapacitor cells were constructed to investigate the electrochemical behavior of the hemp-derived activated carbons, which were used as either positive or negative electrode materials in supercapacitor cells. Here, Hurd-a-5 was used as the working electrode, and a Li-plate was used as the counter electrode (which was also treated as the reference electrode). The electrolyte was 1M LiPF6 in EC:DMC. Note that 1.8M TEABF4 in PC, which was the electrolyte used in the symmetric supercapacitor cells, is not suitable for the asymmetric cells. The CV curves of the carbon/Li hybrid supercapacitor cells exhibit similar quasi-rectangular shapes in various voltage windows, as shown in Fig. S4 in supplemental materials. The specific capacitance calculated from the CVs are 216.6 F/g (voltage window: 2.74.2 V) and 202.9 F/g (voltage window: 1.2-2.7 V). According to the EIS results shown in Fig. S5 in supplemental materials, the ESR is $5.18 \mathrm{ohm}$ for Hurd-a-5 as positive electrode and $5.59 \mathrm{ohm}$ 
for Hurd-a-5 as negative electrode. There is no significant difference in the electrochemical behavior between the Hurd-a-5-based positive electrode and the Hurd-a-5-based negative electrode. A comparison of the electrochemical performance of the symmetric supercapacitor cells with different electrolytes shown in Fig. S6 in supplemental materials reveals that $1.8 \mathrm{M}$ TEABF4 in PC is a superior electrolyte to 1M LiPF6 in EC:DMC for the symmetric supercapacitor cells developed in this work.

\section{Qualitative analysis of specific area capacitance}

It is known that the energy of an electrochemical double-layer capacitor is physically stored in an electrochemical double layer at the interface of electrode and electrolyte. Several models have been developed to discuss EDL. Helmholtz ${ }^{26}$ proposed a simple EDL model, in which electrolyte counterions are attracted to electrodes and strongly compacted near the electrodes, forming an EDL at the electrode/electrolyte interface. In the Helmholtz model, all of the counterions are assumed to be adsorbed on the surface of the electrodes, and the thickness of the EDL is the effective radius of the ions ${ }^{27,28}$. In the model developed by Gouy ${ }^{29}$ and Chapman ${ }^{30}$, the ions in electrolyte are mobile rather than compact on the surface of the electrodes, which is driven by diffusion and electrostatic interaction. Assuming constant electrolyte permittivity, the local electric potential in an electrolyte can be calculated by the Poisson-Boltzmann equation ${ }^{31}$. Stern ${ }^{32}$ introduced a compact layer to the GC (Gouy and Chapman) model and developed a GCS (Gouy, Chapman and Stern) model. In the GCS model, an EDL consists of a compact layer (Stern layer) and a diffuse layer. Various improvements have been made into the GC and GCS

models, including the effects of ion sizes and field-dependent permittivity ${ }^{33}$. Following the concept of the GCS model and using the Poisson-Boltzmann equation, the effects of pore size, 
porosity, pore shape, electrolyte concentration, etc. on the capacitance of the EDL have been discussed ${ }^{34-37}$.

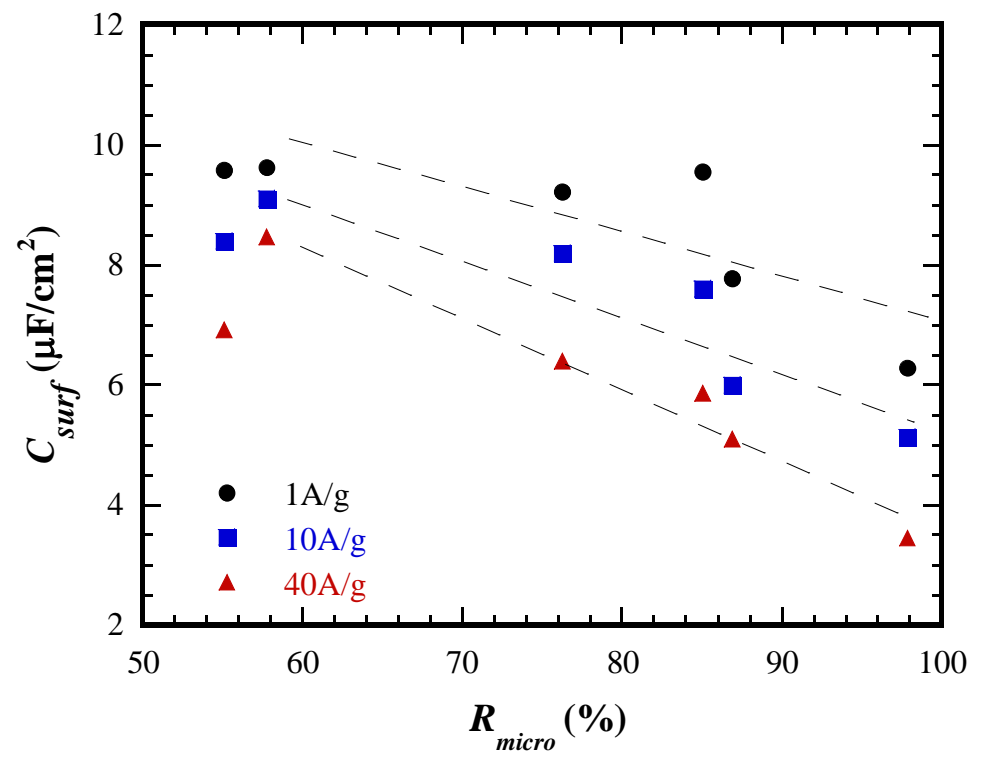

Figure 8. Variation of the specific area capacitance with the fraction of the surface area of micropores for all of the supercapacitor cells made from the activated carbons of Hurd-x-y and Bast-x-y with three current intensities.

To analyze the experimental results within the framework of the EDL models, the specific area capacitance, $C_{\text {surf }}$, was calculated from the specific capacitance as,

$$
C_{\text {surf }}=100 C_{s p} / S_{D F T}
$$

where $S_{D F T}$ is the specific surface area $\left(\mathrm{m}^{2} / \mathrm{g}\right)$ calculate from the DFT method. Centeno and Stoeckli ${ }^{38}$ pointed out that there are several weaknesses in using the BET surface area to calculate the specific area capacitance of $C_{\text {surf }}$, especially for cylindrical micropores. Here, the DFT surface area was used in the calculation of $C_{\text {surf. }}$ Figure 8 shows the variation of the specific area capacitance with the fraction of the surface area of micropores for all of the electrochemical capacitors made from the activated carbons of Hurd-x-y and Bast-x-y with three current intensities. Here, $R_{\text {micro }}$ is defined as the fraction of the surface area of micropores. In general, the 
specific area capacitance displays the decrease trend with increasing the fraction of the surface area of micropores for $R_{\text {micro }}>57 \%$. Such behavior can be attributed to the coupling effect of the ion sizes and the pore sizes. Mesopores allow the formation of an EDL consisting of a stern layer and a diffuse layer ${ }^{33,37}$. Micropores (the pore radius is less than $2 \mathrm{~nm}$ ) cannot accommodate a compact layer of organic ions, and ions form a thread in a micropore ${ }^{39}$ in which mobile ions can migrate along the axis of the pore. The ions in micropores form an EDL more like a diffusion layer.

According the GCS model, the total capacitance of a mesopore can be calculated as

$$
C^{-1}=C_{s}^{-1}+C_{d}^{-1}
$$

where $C_{s}$ is the capacitance of the Stern layer and $C_{d}$ is the capacitance of the diffuse layer. Note that the capacitance in a mesopore is found to be mainly determined by the Stern layer capacitance for both spherical pores ${ }^{39}$ and cylindrical pores ${ }^{37}$. In addition, the capacitance of the Stern layer and total capacitance increase with the increase of the pore size, and the total capacitance also increases with the increase of the thickness of the Stern layer ${ }^{33}$. The capacitance without a Stern layer is significantly smaller than that with a Stern layer. Based on the above discussion, the capacitance of a single micropore, which only has a diffuse layer, is much smaller than that of a single mesopore with a Stern layer and a diffusion layer. The difference in the capacitance between a micropore and a mesopore will further increase with increasing pore size.

For activated carbons with a distribution of pore sizes, one can approximately separate the pores into micropores (pore size $<2 \mathrm{~nm}$ ) and mesopores $(2 \mathrm{~nm}<$ pore size $<50 \mathrm{~nm}$ ). Using the rule of mixtures, the specific area capacitance can be calculated as

$$
C_{\text {surf }}=C_{\text {micro }} R_{\text {micro }}+C_{\text {meso }} R_{\text {meso }}=C_{\text {meso }}+\left(C_{\text {micro }}-C_{\text {meso }}\right) R_{\text {micro }}
$$


where $C_{\text {micro }}$ and $C_{m e s o}$ are the average specific capacitances of micropores and mesopores, respectively, and $R_{\text {meso }}$ is the fraction of the surface area of mesopores.

With $C_{\text {micro }}$ being less than $C_{\text {meso }}$, as discussed above, Eq. (7) suggests the specific area capacitance decreases linearly with the increase of $R_{\text {micro }}$ in accord with the experimental data shown in Fig. 8 for the supercapacitor cells made from the activated carbons with $R_{\text {micro }}$ larger than $57 \%$. The reason for the deviation of the specific area capacitance with $R_{\text {micro }}=55.1 \%$ from the linear relation is unclear. It might be due to other size effects, such as the ratio of the pore length to the pore radius. From Fig. 8, one notes that there exists effect of current density on the specific area capacitance. For supercapacitor cells with the same fraction of micropores, a larger specific area capacitance can be achieved via a smaller current density. Such behavior is likely controlled by the migration of ions to reach the equilibrium state. There exists a larger resistance to the migration of the ions of organic electrolyte in micropores than the migration of ions of organic electrolyte in mesopores. The resistance likely increases with the increase of current density, which causes the motion of a cloud of ions. Under the action of a small current density, ions have enough time to migrate and form an EDL at the equilibrium state. A diffusion layer is formed over a relatively larger portion of the surface areas in pores, resulting in a higher capacitance.

\section{Summary}

In summary, activated carbons were prepared from raw hemp stem (hurd and bast) as the precursors via hydrothermal processing and chemical activation. Controlling the experimental conditions, activated carbons of low-dimensional structures with high surface area and large fraction of mesopores were formed. The activated carbons were used to construct the electrodes of supercapacitor cells. The electrochemical performance of the cells was characterized. 
Excellent electrochemical performance of a specific capacitance of $160 \mathrm{~F} / \mathrm{g}$ and a high energy density of $19.8 \mathrm{Wh} / \mathrm{kg}$ at a power density of $21 \mathrm{~kW} / \mathrm{kg}$ was achieved. Both the specific capacitance and capacitive retention increase with the increase of the surface area and fraction of the mesopores. For the same mass ratio of 5:1 for $\mathrm{KOH} / \mathrm{biochar}$ and liquid solution (DI water or sulfuric acid), the supercapacitor cells made from the activated carbons of Hurd-x-5 possess higher capacitance than those made from the activated carbons Bast- $x-5$. The specific capacitance gradually decreases with increasing current density, and the supercapacitor cells made from the activated carbons prepared by using sulfuric acid in the hydrothermal process feature high capacitive retention.

A simple relationship between the specific area capacitance and the fraction of micropores was proposed, via the rule of mixtures. The experimental results support the relationship for the supercapacitor cells made from the activated carbons with $R_{\text {micro }}$ larger than $57 \%$. There exists the effect of current density on the specific area capacitance. For supercapacitor cells with the same fraction of micropores, a larger specific area capacitance can be achieved via a smaller electric current.

The process reported in this study provides an economic and effective method to prepare electrochemically active materials of high-performance from biomass and biowastes. The usage of low cost biomass can further reduce the cost of the material syntheses and provide the possibility to economically produce activated carbon materials in a large quantity.

Acknowledgements: The authors would like to acknowledge the financial support of NSF 1355438 Powering the Kentucky Bioeconomy for a Sustainable Future. FY is grateful for the 
financial support from the KSEF (KSEF-148-502-15-341). We also thank Joanna Mroczkowska for conducting the surface area analysis.

\section{References:}

1. A. Burke, Journal of Power Sources, 2000, 91, 37-50.

2. A. S. Arico, P. Bruce, B. Scrosati, J.-M. Tarascon and W. Van Schalkwijk, Nature Materials, 2005, 4, 366-377.

3. A. Chu and P. Braatz, Journal of Power Sources, 2002, 112, 236-246.

4. L. L. Zhang and X. Zhao, Chemical Society Reviews, 2009, 38, 2520-2531.

5. G. Yu, L. Hu, M. Vosgueritchian, H. Wang, X. Xie, J. R. McDonough, X. Cui, Y. Cui and Z. Bao, Nano Letters, 2011, 11, 2905-2911.

6. B. J. Lee, S. Sivakkumar, J. M. Ko, J. H. Kim, S. M. Jo and D. Y. Kim, Journal of Power Sources, 2007, 168, 546-552.

7. Y.-Y. Horng, Y.-C. Lu, Y.-K. Hsu, C.-C. Chen, L.-C. Chen and K.-H. Chen, Journal of Power Sources, 2010, 195, 4418-4422.

8. Y. Zhu, S. Murali, M. D. Stoller, K. Ganesh, W. Cai, P. J. Ferreira, A. Pirkle, R. M. Wallace, K. A. Cychosz and M. Thommes, Science, 2011, 332, 1537-1541.

9. A. Pandolfo and A. Hollenkamp, Journal of Power Sources, 2006, 157, 11-27.

10. Y. Wang, Z. Shi, Y. Huang, Y. Ma, C. Wang, M. Chen and Y. Chen, The Journal of Physical Chemistry C, 2009, 113, 13103-13107.

11. R. Demir-Cakan, P. Makowski, M. Antonietti, F. Goettmann and M.-M. Titirici, Catalysis Today, 2010, 150, 115-118.

12. R. Cakan, Chemical Communications, 2008, 3759-3761. 
13. S.-A. Wohlgemuth, F. Vilela, M.-M. Titirici and M. Antonietti, Green Chemistry, 2012, 14, 741-749.

14. M.-M. Titirici, M. Antonietti and N. Baccile, Green Chemistry, 2008, 10, 1204-1212.

15. C. Falco, N. Baccile and M.-M. Titirici, Green Chemistry, 2011, 13, 3273-3281.

16. X. Cui, M. Antonietti and S. H. Yu, Small, 2006, 2, 756-759.

17. M. M. Titirici, A. Thomas, S.-H. Yu, J.-O. Müller and M. Antonietti, Chemistry of Materials, 2007, 19, 4205-4212.

18. H.-S. Qian, S.-H. Yu, L.-B. Luo, J.-Y. Gong, L.-F. Fei and X.-M. Liu, Chemistry of Materials, 2006, 18, 2102-2108.

19. P. Ranalli and G. Venturi, Euphytica, 2004, 140, 1-6.

20. H. Wang, Z. Xu, A. Kohandehghan, Z. Li, K. Cui, X. Tan, T. J. Stephenson, C. K. King’ondu, C. M. Holt and B. C. Olsen, ACS Nano, 2013, 7, 5131-5141.

21. N. Stevulova, J. Cigasova, A. Estokova, E. Terpakova, A. Geffert, F. Kacik, E. Singovszka and M. Holub, Materials, 2014, 7, 8131-8150.

22. P. Taberna, P. Simon and J.-F. Fauvarque, Journal of The Electrochemical Society, 2003, 150, A292-A300.

23. B. E. Conway, Electrochemical supercapacitors: scientific fundamentals and technological applications, Springer Science \& Business Media, 2013.

24. D. W. Wang, F. Li, M. Liu, G. Q. Lu and H. M. Cheng, Angewandte Chemie, 2008, 120, 379-382.

25. H. J. Keh and S. B. Chen, Journal of Fluid Mechanics, 1988, 194, 377-390.

26. H. V. Helmholtz, Annalen der Physik, 1879, 243, 337-382. 
27. A. J. Bard and L. R. Faulkner, Electrochemical methods: fundamentals and applications, Wiley New York, 1980.

28. J. H. Masliyah and S. Bhattacharjee, Electrokinetic and colloid transport phenomena, John Wiley \& Sons, 2006.

29. G. Gouy, Journal de Physique 1910, 9, 457-467.

30. D. L. Chapman, The London, Edinburgh, and Dublin Philosophical Magazine and Journal of Science, 1913, 25, 475-481.

31. M. Mitchell, R. Qiao and N. Aluru, J. Journal of Microelectromech Systems 2000, 9, 435449.

32. O. Stern, Zeitschrift Fur Elektrochemie, 1924, 30, 1014-1020.

33. H. Wang and L. Pilon, The Journal of Physical Chemistry C, 2011, 115, 16711-16719.

34. J. Varghese, H. Wang and L. Pilon, Journal of The Electrochemical Society, 2011, 158, A1106-A1114.

35. H. Wang, J. Varghese and L. Pilon, Electrochimica Acta, 2011, 56, 6189-6197.

36. H. Wang, J. Fang and L. Pilon, Electrochimica Acta, 2013, 109, 316-321.

37. J. Huang, R. Qiao, B. G. Sumpter and V. Meunier, Journal of Materials Research , 2010, 25, 1469-1475.

38. T. Centeno and F. Stoeckli, Electrochimica Acta, 2011, 56, 7334-7339.

39. J. Huang, B. G. Sumpter and V. Meunier, Angewandte Chemie International Edition, 2008, 47, 520-524. 
Graphical abstract

\section{Hemp-derived activated carbons for supercapacitors}

Wei Sun ${ }^{a}$, Stephen M. Lipka ${ }^{b}$, Christopher Swartz ${ }^{b}$, David Williams ${ }^{c}$, and Fuqian Yang ${ }^{a *}$

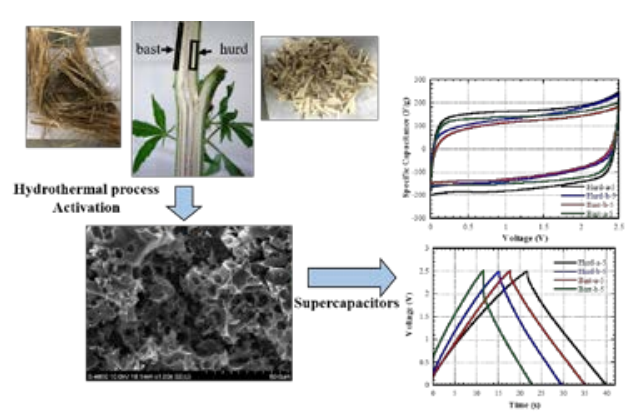

